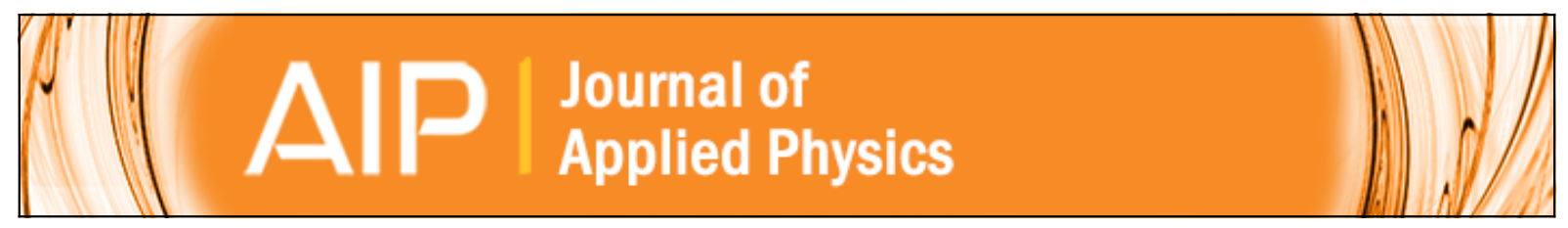

\title{
Luminescent properties and electronic structure of conjugated polymer-dielectric nanocrystal composites
}

S. Musikhin, L. Bakueva, E. H. Sargent, and A. Shik

Citation: Journal of Applied Physics 91, 6679 (2002); doi: 10.1063/1.1470239

View online: http://dx.doi.org/10.1063/1.1470239

View Table of Contents: http://scitation.aip.org/content/aip/journal/jap/91/10?ver=pdfcov

Published by the AIP Publishing

\section{Articles you may be interested in}

Theory of exciton transfer and diffusion in conjugated polymers

J. Chem. Phys. 141, 164103 (2014); 10.1063/1.4897986

Electronic structure disorder, vibronic coupling, and charge transfer excitons in poly(fluorene-altbithiophene):fullerene films

Appl. Phys. Lett. 102, 113302 (2013); 10.1063/1.4796118

Optical properties of conjugated poly(3-hexylthiophene)/ [ 6, 6 ] - phenyl C 61 -butyric acid methyl ester composites

J. Appl. Phys. 102, 083104 (2007); 10.1063/1.2799049

Poly(2-methoxy-5-( 2 ' -ethyl-hexyloxy)-1,4-phenylenevinylene) conjugated polymer domains in a thermoplastic polyurethane matrix

J. Appl. Phys. 101, 033133 (2007); 10.1063/1.2437158

Luminescence of bulk and nanocrystalline cubic yttria

J. Appl. Phys. 90, 3516 (2001); 10.1063/1.1388022

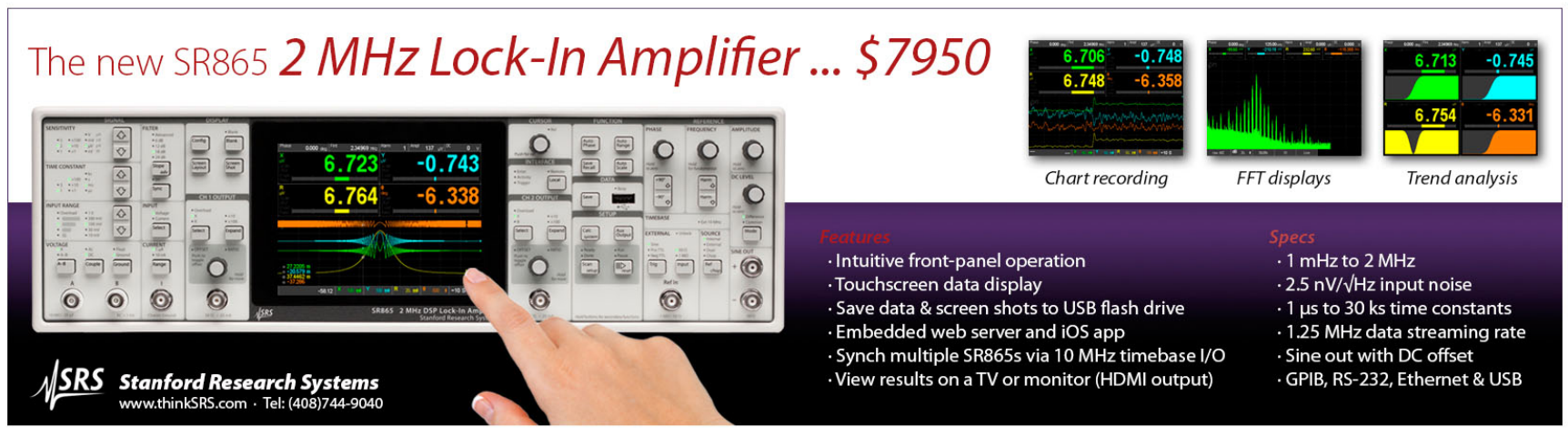




\title{
Luminescent properties and electronic structure of conjugated polymer-dielectric nanocrystal composites
}

\author{
S. Musikhin, L. Bakueva, ${ }^{a}$ E. H. Sargent, and A. Shik \\ Department of Electrical and Computer Engineering, University of Toronto, 10 King's College Road, \\ Toronto, Ontario M5S 3G4, Canada
}

(Received 4 December 2001; accepted for publication 25 February 2002)

\begin{abstract}
We report results of experimental investigations of the luminescent properties of two different conjugated polymers in which we embedded nanocrystals of $\mathrm{Al}_{2} \mathrm{O}_{3}, \mathrm{Y}_{2} \mathrm{O}_{3}, \mathrm{ZnO}$, and $\mathrm{SnSbO}$. The dielectric nanocrystals result in a blueshifting and broadening of luminescence spectra of poly ( $p$-phenylene vinylene) with a simultaneous disappearance of its vibronic structure. The same nanocrystals in a poly[2-(6-cyano- $6^{\prime}$-methylheptyloxy)-1,4-phenylene] matrix cause redshifting and spectral broadening. These observations are explained by referring to a model that accounts for the change in the polarization component of the carrier and exciton energy in the vicinity of inclusions. () 2002 American Institute of Physics. [DOI: 10.1063/1.1470239]
\end{abstract}

\section{INTRODUCTION}

Embedding metallic, ${ }^{1}$ semiconducting, ${ }^{2}$ and dielectric $^{3}$ nanocrystals into polymer matrices is an area of current interest in nanotechnology research. Inorganic nanoparticles can substantially influence the mechanical, electrical, and optical (including nonlinear ${ }^{4}$ optical as well as photoluminescent, electroluminescent, and photoconductive ${ }^{5-7}$ ) properties of the polymer in which they are included.

The influence of dielectric nanocrystals on the properties of conducting polymers has been investigated much less so far. There is work reported that is devoted to $\mathrm{TiO}_{2}$ inclusions in conducting polymers. ${ }^{3}$ Their influence on the photoelectric properties of nanocomposites is explained with regard to the fact that $\mathrm{TiO}_{2}$ particles usually form a type-II heterojunction with a polymer matrix, which essentially results in the separation of nonequilibrium electrons and holes. ${ }^{8}$ Embedding $\mathrm{SiO}_{2}$ particles ${ }^{9}$ results in stabilization of the nanocomposite properties and an increase in the lifetime of polymer-based electroluminescent devices.

It is usually assumed that embedding semiconducting or dielectric nanocrystals creates additional potential wells and/or barriers for carriers and does not influence the energy spectrum of the polymer itself, except for a possible implicit influence through a change of the polymer conjugated length. ${ }^{10}$ However, it is known that, in a conducting polymer with a very low carrier mobility, the energy of carriers is determined to a considerable degree by the polarization of the material, ${ }^{11}$ which influences the position of the highest occupied molecular orbital (HOMO) and lowest unoccupied molecular orbital (LUMO) levels as well as the exciton energy. The influence can be considerable, and can result in energy shifts of the order of $1 \mathrm{eV}$ for free (unbound) electrons and holes in a polymer. In a uniform polymer medium this component of energy is determined by the molecular structure of the polymer and the fabrication technology. In nonuniform media, such as polymer-nanocrystal mixtures,

a)Electronic email: luda.bakoueva@utoronto.ca the picture may change. In that case the polarization energy component may additionally depend on the relative position of carriers and inorganic inclusions.

In this work we investigate the influence of dielectric inclusions on the energy spectrum of a conducting polymer and on its luminescence behavior.

\section{DESCRIPTION OF EXPERIMENT}

For the present work the following polymer matrix materials were chosen: $\operatorname{poly}(p$-phenylene vinylene) (PPV) and poly[2-(6-cyano- $6^{\prime}$-methylheptyloxy)-1,4-phenylene] (CN-PPP). Both materials were fabricated from prepolymer solutions manufactured by Lark Enterprises (PPV) and American Dye Source, Inc. (CN-PPP). While the properties of CN-PPV are much less well understood than those of PPV, CN-PPP is known to have a considerably larger energy gap and to have absorption and photoluminescence maxima lying at 3.70 and $3.08 \mathrm{eV},{ }^{12}$ respectively.

We used the following nanocrystals as antidots: dielectric oxides $\mathrm{Y}_{2} \mathrm{O}_{3}, \mathrm{Al}_{2} \mathrm{O}_{3}$, and $\mathrm{ZnO}$ and antimony-tin oxide $\mathrm{SnO}_{2} / \mathrm{Sb}_{2} \mathrm{O}_{3} / \mathrm{Sb}_{2} \mathrm{O}_{5}$ (abbreviated throughout the present work as $\mathrm{SnSbO}$ ). These were reported by the supplier (Nanophase Technologies Corporation) to be an average size of $25 \mathrm{~nm}\left(\mathrm{Y}_{2} \mathrm{O}_{3}\right), 38 \mathrm{~nm}\left(\mathrm{Al}_{2} \mathrm{O}_{3}\right)$, and $54 \mathrm{~nm}(\mathrm{ZnO})$. We present in Table I the available values of band gap $E_{g}$ and electron affinity $\phi$ of these materials, as well as of the static $\varepsilon_{0}$ and high-frequency $\varepsilon_{\infty}$ dielectric permittivities responsible for polaron effects. Comparison with $E_{g}$ and $\phi$ for PPV (for CN-PPP no data on $\phi$ are available) suggests that a type-I heterojunction should exist between $\mathrm{Al}_{2} \mathrm{O}_{3}$ and $\mathrm{Y}_{2} \mathrm{O}_{3}$ and their host polymer-thus these dielectric nanocrystals are antidots for both electrons and holes-whereas between $\mathrm{SaSbO}$ and $\mathrm{ZnO}$ and the host polymers, type-II heterojunctions are formed (Fig. 1).

Composite samples were prepared by mixing the nanocrystal powder with a polymer precursor followed by sonication for $1.5 \mathrm{~h}$ and spin coating onto glass substrates. The 
TABLE I. Energy parameters and dielectric permittivity of composite structure materials.

\begin{tabular}{lcccc}
\hline \hline Material & $\begin{array}{c}E_{g} \\
(\mathrm{eV})\end{array}$ & $\begin{array}{c}\phi \\
(\mathrm{eV})\end{array}$ & $\varepsilon_{\infty}$ & $\varepsilon_{0}$ \\
\hline $\mathrm{Al}_{2} \mathrm{O}_{3}$ & $8.8^{\mathrm{a}}$ & $1^{\mathrm{a}}$ & $3.4^{\mathrm{a}}$ & $8.5^{\mathrm{k}}$ \\
$\mathrm{Y}_{2} \mathrm{O}_{3}$ & $6^{\mathrm{a}}$ & $2^{\mathrm{a}}$ & $4.4^{\mathrm{a}}$ & $14^{1}$ \\
$\mathrm{ZnO}$ & $3.35^{\mathrm{b}}$ & $4.2^{\mathrm{c}}$ & $4.0^{\mathrm{d}}$ & $8.5^{\mathrm{d}}$ \\
$\mathrm{SnSbO}$ & $\sim 2.9^{\mathrm{e}}$ & $4.49^{\mathrm{f}}$ & & \\
$\mathrm{PPV}$ & $2.5^{\mathrm{g}}$ & $2.6^{\mathrm{g}}$ & $3-7.8^{\mathrm{h}}$ & $>11.6^{\mathrm{j}}$ \\
$\mathrm{CN}-\mathrm{PPP}$ & $3.7^{\mathrm{i}}$ & & & \\
\hline \hline
\end{tabular}

${ }^{\mathrm{a}}$ Reference 13.

${ }^{\mathrm{b}}$ Reference 14.

${ }^{\mathrm{c}}$ Reference 15 .

${ }^{\mathrm{d}}$ Reference 16

e Reference 17.

${ }^{\mathrm{f}}$ Reference 18.

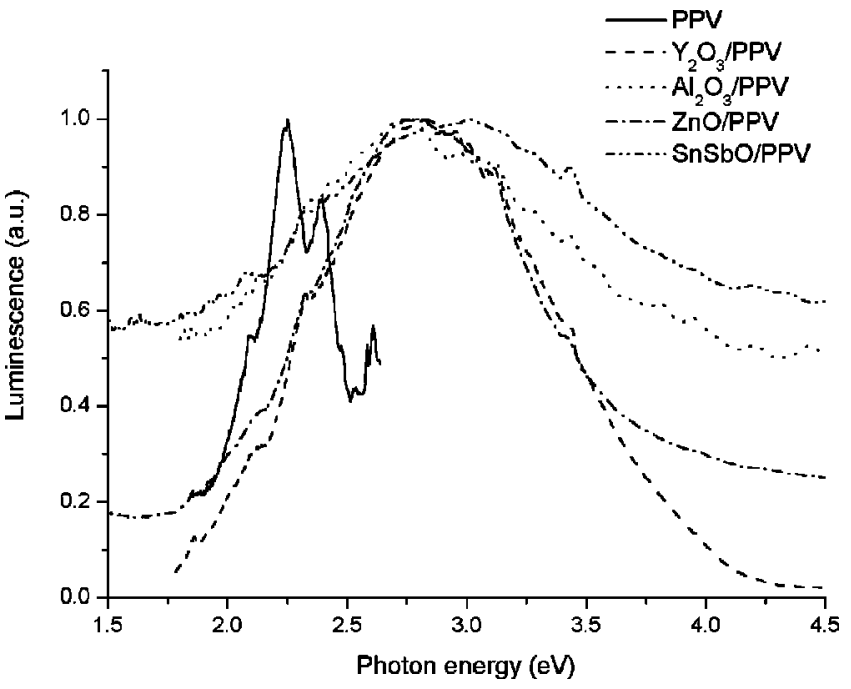

FIG. 2. Normalized photoluminescence spectra of pure PPV and nanocomposites $\mathrm{Al}_{2} \mathrm{O}_{3} / \mathrm{PPV}, \mathrm{Y}_{2} \mathrm{O}_{3} / \mathrm{PPV}, \mathrm{SnSbO} / \mathrm{PPV}$, and $\mathrm{ZnO} / \mathrm{PPV}$ with volume fractions of $\sim 10 \%$.

ticle material. The maximum position in SnSbO/PPV nanocomposites is seen to be shifted towards higher energies relative to in other composites and it is equal to $3.0 \mathrm{eV}$, compared with 2.7-2.8 eV in $\mathrm{Y}_{2} \mathrm{O}_{3}, \mathrm{Al}_{2} \mathrm{O}_{3}$, and $\mathrm{ZnO}$.

The luminescence excitation spectrum in nanocomposites is also modified significantly, as shown in Fig. 3. Instead of a maximum at $2.5-4.0 \mathrm{eV}$, wide absorption regions appear at higher energies. In the spectra of $\mathrm{Al}_{2} \mathrm{O}_{3} / \mathrm{PPV}$ and $\mathrm{Y}_{2} \mathrm{O}_{3} / \mathrm{PPV}$ the local maximum lies at $2.8-4.0 \mathrm{eV}$ whereas absorption for $\mathrm{ZnO} / \mathrm{PPV}$ and $\mathrm{SnSbO} / \mathrm{PPV}$ composites drops monotonically with a decrease in photon energy.

Photoluminescence spectra of pure CN-PPP- and CNPPP-based nanocomposites with $\mathrm{Y}_{2} \mathrm{O}_{3}, \mathrm{Al}_{2} \mathrm{O}_{3}, \mathrm{ZnO}$, and $\mathrm{SnSbO}$ dielectric nanoparticles are presented in Figs. 4 and 5. As is seen the luminescence spectra of CN-PPP are modified by nanoparticles less noticeably than those of the PPVbased nanocomposites. The luminescence maximum acquires

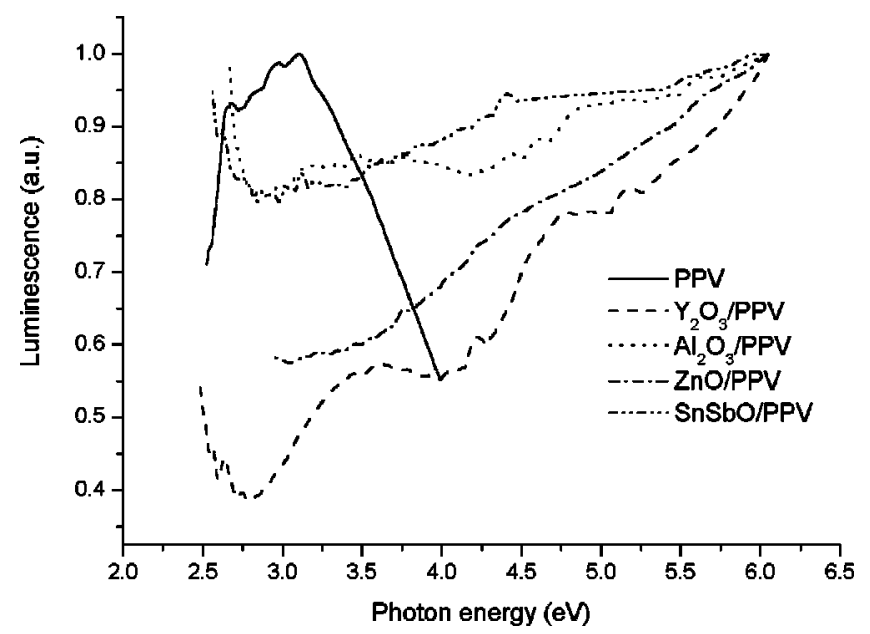

FIG. 3. Normalized excitation spectra of pure PPV and nanocomposites $\mathrm{Al}_{2} \mathrm{O}_{3} / \mathrm{PPV}, \mathrm{Y}_{2} \mathrm{O}_{3} / \mathrm{PPV}, \mathrm{SnSbO} / \mathrm{PPV}$, and $\mathrm{ZnO} / \mathrm{PPV}$ with volume fractions $\sim 10 \%$. The emission wavelength is $490 \mathrm{~nm}$ for $\mathrm{Al}_{2} \mathrm{O}_{3} / \mathrm{PPV}, 533 \mathrm{~nm}$ for $\mathrm{Y}_{2} \mathrm{O}_{3} / \mathrm{PPV}$, and $510 \mathrm{~nm}$ for $\mathrm{SnSbO} / \mathrm{PPV}$ and $\mathrm{ZnO} / \mathrm{PPV}$.
FIG. 1. Characteristic energy levels in nanocomposite components. The electron affinity in CN-PPP is an estimated value. 


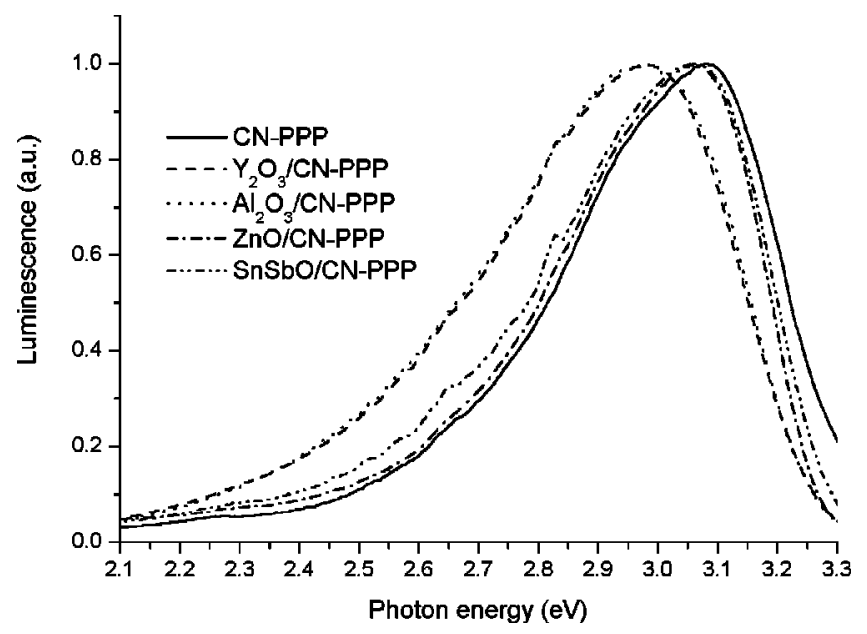

FIG. 4. Normalized photoluminescence spectra of pure CN-PPP and nanocomposites $\mathrm{Al}_{2} \mathrm{O}_{3} / \mathrm{CN}-\mathrm{PPP}, \mathrm{Y}_{2} \mathrm{O}_{3} / \mathrm{CN}-\mathrm{PPP}, \mathrm{SnSbO} / \mathrm{CN}-\mathrm{PPP}$, and $\mathrm{ZnO} /$ CN-PPP with volume fractions of $\sim 10 \%$.

a small redshift from $3.085 \mathrm{eV}$ in pure CN-PPP to the values $3.05 \mathrm{eV}(\mathrm{SnSbO}), 3.06 \mathrm{eV}(\mathrm{ZnO}), 2.98 \mathrm{eV}\left(\mathrm{Y}_{2} \mathrm{O}_{3}\right)$, and 2.96 $\mathrm{eV}\left(\mathrm{Al}_{2} \mathrm{O}_{3}\right)$ in the composites containing $\sim 10 \%$ (by volume) of nanoparticles. The increase of nanoparticle volume up to $60 \%$ causes almost no change in the position of the maximum for $\mathrm{SnSbO} / \mathrm{CN}-\mathrm{PPP}$ and $\mathrm{ZnO} / \mathrm{CN}-\mathrm{PPP}$, changes the maximum to $2.93 \mathrm{eV}$ for $\mathrm{Y}_{2} \mathrm{O}_{3} / \mathrm{CN}-\mathrm{PPP}$, and to $2.84 \mathrm{eV}$ for $\mathrm{Al}_{2} \mathrm{O}_{3} / \mathrm{CN}-\mathrm{PPP}$, and noticeably broadens the spectrum and increases the intensity of luminescence at lower photon energies (Fig. 5). The spectrum of $\mathrm{SnSbO/CN-PPP} \mathrm{shows} \mathrm{an}$ additional shoulder at $2.88 \mathrm{eV}$, suggesting an added luminescence mechanism may play a role inside the composite compared to in the pure matrix.

The luminescence excitation spectra for composites with a high percentage of nanocrystals always contain a maximum at photon energies $3.43 \mathrm{eV}\left(\mathrm{Y}_{2} \mathrm{O}_{3} / \mathrm{CN}-\mathrm{PPP}\right), 3.37 \mathrm{eV}$ $\left(\mathrm{Al}_{2} \mathrm{O}_{3} / \mathrm{CN}-\mathrm{PPP}\right), 3.45 \mathrm{eV}$ (SnSbO/CN-PPP), and $3.67 \mathrm{eV}$ (ZnO/CN-PPP) (Fig. 6). This maximum for the $\mathrm{ZnO} / \mathrm{CN}-\mathrm{PPP}$ nanocomposite coincides with that for pure CN-PPP.

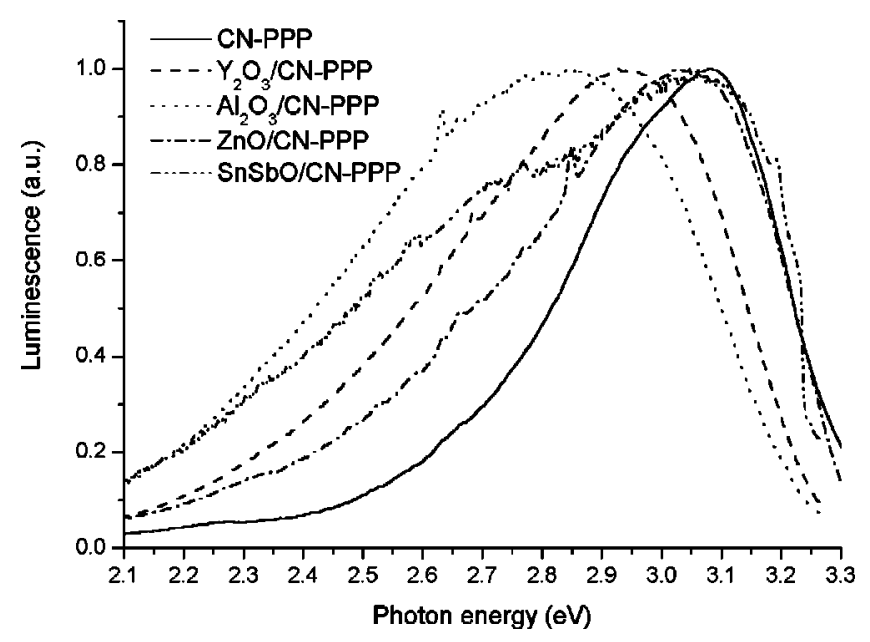

FIG. 5. Normalized photoluminescence spectra of pure CN-PPP and nanocomposites $\mathrm{Al}_{2} \mathrm{O}_{3} / \mathrm{CN}-\mathrm{PPP}, \mathrm{Y}_{2} \mathrm{O}_{3} / \mathrm{CN}-\mathrm{PPP}, \mathrm{SnSbO} / \mathrm{CN}-\mathrm{PPP}$, and $\mathrm{ZnO} /$ $\mathrm{CN}$-PPP with the volume fractions of $\sim 60 \%$.

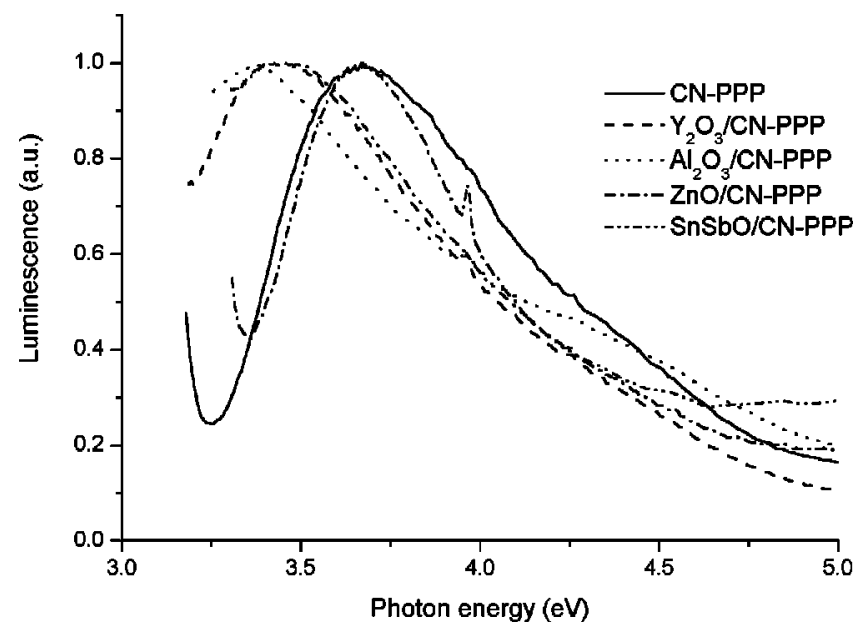

FIG. 6. Normalized excitation spectra of pure CN-PPP and nanocomposites $\mathrm{Al}_{2} \mathrm{O}_{3} / \mathrm{CN}-\mathrm{PPP}, \mathrm{Y}_{2} \mathrm{O}_{3} / \mathrm{CN}-\mathrm{PPP}, \mathrm{SnSbO} / \mathrm{CN}-\mathrm{PPP}$, and $\mathrm{ZnO} / \mathrm{CN}-\mathrm{PPP}$ with volume fractions of $\sim 60 \%$.

\section{DISCUSSION}

We now analyze how the observed influence of nanocrystals on the composite spectra may be accounted for by considering the difference in polarization properties between the dielectric nanocrystals and the polymer matrix. In conducting polymers, polaron effects shift the energy levels, ${ }^{24}$ decreasing the HOMO-LUMO gap and reducing therefore the luminescence energy. The polaron shift $W$ arises due to interactions between an electron and not only its nearest neighbors, but also atoms from higher coordination spheres. In the composite molecules considered herein, some polymer molecules are in the close vicinity of an antidot which has a lower polarizability $\varepsilon_{\text {eff }}=\left(1 / \varepsilon_{\infty}-1 / \varepsilon_{0}\right)^{-1}$ than the polymer. This decreases the polaron shift $W$ and increases the energy of the luminescence peak.

We now quantify this effect. The main contribution ${ }^{25}$ to the polaron shift $W$ comes from the interaction of localized charge with dipoles induced at surrounding molecules. This varies with the intermolecular distance $r_{i}$ as $r_{i}^{-4}$ so that $W$ is proportional to $\Sigma_{i} r_{i}^{-4}$. Since the number of particles that noticeably contribute to $W$ is in the thousands, ${ }^{25}$ we replace summation by integration, beginning at the nearest-neighbor distance $r_{0}$. This gives $W_{0} \simeq A \int_{r_{0}}^{\infty} d^{3} \mathbf{r} / r^{4}=4 \pi A / r_{0}$, where $A$ accounts for the interaction constant and also the concentration of molecules. The subscript 0 in $W_{0}$ denotes the value in the unperturbed matrix. If the molecule we consider lies at a distance $a$ from a dielectric that does not contribute to the polarization, then the region with $r>a \cos \theta$ belonging to the dielectric must be excluded from the integration. This gives

$$
W=W_{0}\left\{\begin{array}{cc}
1 / 2+a / 4 r_{0}, & a<r_{0} ; \\
1-r_{0} / 4 a, & a>r_{0}
\end{array} ; \equiv W_{0} f\left(a / r_{0}\right) .\right.
$$

To obtain the luminescence spectrum, we must average over all possible $a$. Let us assume that the spectrum of a pure polymer represents a line centered at photon energy $\hbar \omega_{0}$ $=E_{g 0}-W_{0}$ (where $E_{g 0}$ is a HOMO-LUMO gap in the absence of polaron effects) and is described by some spectral shape $s\left(\hbar \omega-E_{g 0}+W_{0}\right)$. If antidots are spheres of radius $R$ 


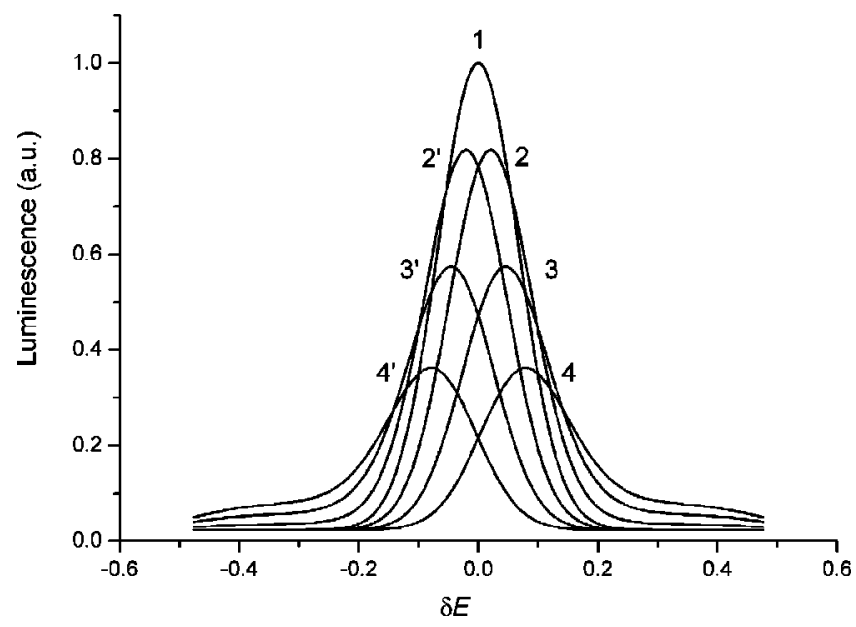

FIG. 7. Model calculations of influence of inclusions on polymer photoluminescence spectra. Right shift of maximum (2, 3, 4 curves) is associated with the smaller polarizability of inclusions vs the polymer matrix polarizability and left shift $\left(2^{\prime}, 3^{\prime}, 4^{\prime}\right.$ curves) is associated with the larger polarizability of inclusions. The concentration of inclusions $C$ is 0 for curve 1 , 0.1 for curves 2 and $2^{\prime}, 0.3$ for curves 3 and $3^{\prime}$, and 0.5 for curves 4 and $4^{\prime} . \delta E=\hbar\left(\omega-\omega_{0}\right)$ is measured in units of $\left|W_{0}^{i}-W_{0}^{m}\right|$.

and volume concentration $C$, then $a$ in Eq. (1) can vary from 0 to $R\left(C^{-1 / 3}-1\right)$. The resulting luminescence spectrum is

$$
\begin{aligned}
S(\hbar \omega)= & \frac{3 C}{R^{3}} \int_{0}^{R\left(C^{-1 / 3}-1\right)}(R+a)^{2} s\left[\hbar \omega-E_{g 0}\right. \\
& \left.+W_{0} f\left(a / r_{0}\right)\right] d a .
\end{aligned}
$$

Figure 7 shows the results of calculations with Eq. (2) assuming that $s\left(\hbar \omega-E_{g 0}+W_{0}\right)$ has a Gaussian shape. The presence of antidots should cause a blueshift of the luminescent line which increases with the concentration of the inclusions. The shift does not exceed $0.1 \mathrm{~W}$ but for the $W$ $\sim 1 \mathrm{eV}$ typical of organic crystals ${ }^{25}$ it is enough to explain the experimental data. At large $C$ the line shape becomes asymmetric by acquiring a shoulder from the blue side. For a given $C$, the shift becomes smaller with an increase in $R$ due to a decrease of the total matrix-inclusion interface area.

If inclusions have larger polarizability than the matrix, the effect will be the opposite, resulting in an increase in the polaron shift (decrease in the energy of the luminescent line). In this case, the above calculation may be repeated for the different matrix and inclusion polaron shifts, and Fig. 7 will instead show a negative shift in the luminescence line $W_{0}^{i}$ $-W_{0}^{m}$, with $m$ and $i$ subscripts characterizing the matrix and inclusion, respectively.

The simple calculations presented above demonstrate that if dipoles induced in dielectric inclusions are weaker that those in a polymer, the polarization component of energy diminishes, which, in turn, shifts LUMO upwards (to higher electron energies) and HOMO downwards (to higher hole energies). This results in a greater effective band gap and increased excitonic energy in the vicinity of the inclusions [Fig. 8(a)]. The amplitude of the shift in energy depends on the distance from the inclusions and on their size. In this case both the luminescence and the excitation spectra shift to-

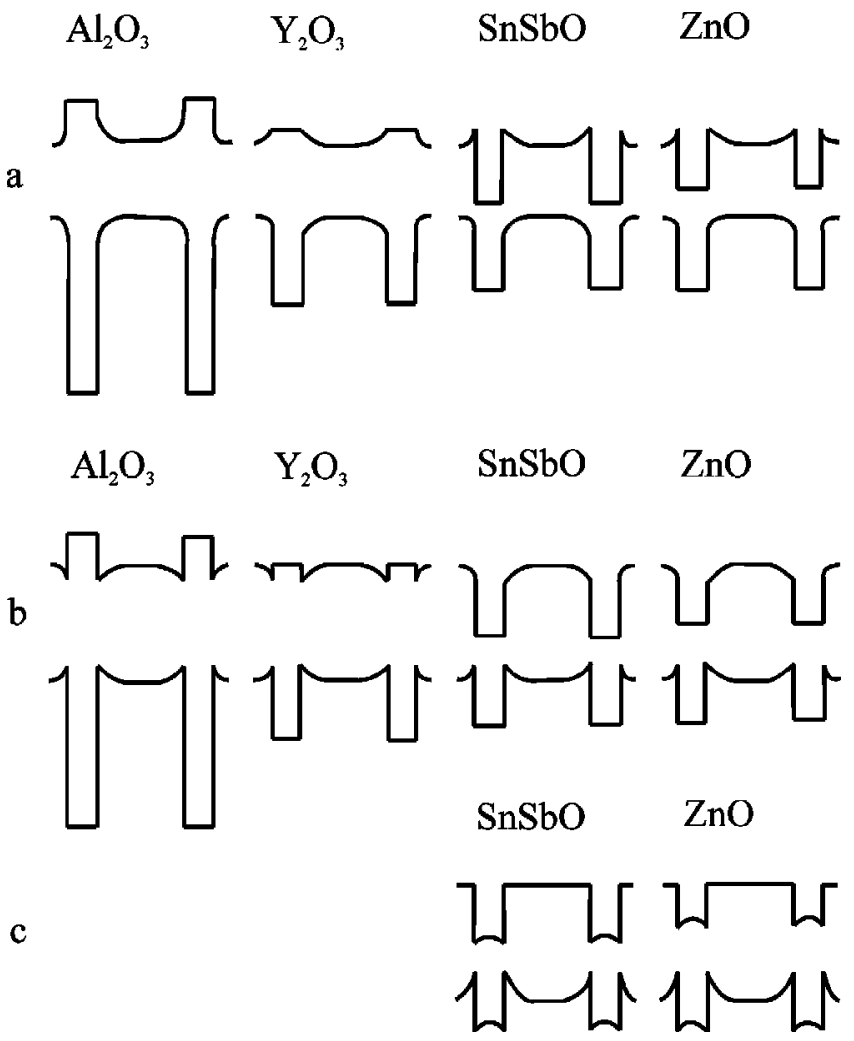

FIG. 8. Band diagrams of nanocomposites $\mathrm{Al}_{2} \mathrm{O}_{3} / \mathrm{PPV}, \mathrm{Y}_{2} \mathrm{O}_{3} / \mathrm{PPV}$, $\mathrm{SnSbO} / \mathrm{PPV}$, and $\mathrm{ZnO} / \mathrm{PPV}$ (a) and of nanocomposites $\mathrm{Al}_{2} \mathrm{O}_{3} / \mathrm{CN}-\mathrm{PPP}$, $\mathrm{Y}_{2} \mathrm{O}_{3} / \mathrm{CN}$-PPP, SnSbO/CN-PPP, and $\mathrm{ZnO} / \mathrm{CN}-\mathrm{PPP}$ (b) and changes in the band diagram of type-II structures at the optical excitation caused by carrier charge redistribution (c).

wards higher photon energies. This situation is presumably realized in PPV-based nanocomposites (Figs. 2 and 3).

An additional mechanism of the blueshift of the luminescence maximum in PPV may be related to changes in the conjugated length. At the sites where the bonds between a polymer chain and nanocrystal are formed, the electronic configuration in the polymer chain changes, $s-p$ hybridization occurs ${ }^{26}$ and the overlapping of $\pi$ orbitals diminishes. The conjugation length therefore decreases, causing the corresponding increase in $E_{g}$.

Measured spectra also reveal the disappearance of vibronic spectra in nanocomposites. This may be attributed to the formation of bonds between polymer chains and nanocrystals, which must be taken into account in the electronphonon Hamiltonian. Since the mass of the nanocrystal exceeds that of a single monomer, the influence of nanocrystals can be treated as a boundary condition that pins two points on the polymer chain so that only vibrations between these points are allowed. In addition, different nanocrystals may have different sizes and masses. These factors together smear out the initially discrete phonon structure and the related vibronic spectra.

If the dipoles formed in inclusions exceed those in a polymer, the polarization energy increases, LUMO levels move downward, and HOMO levels upward. As a result, the band gap and the energies of absorption and luminescence peaks decrease [Fig. (8b)]. The spatial variations of the polarization energy cause simultaneous broadening of the spec- 
trum. This situation is expected in CN-PPP-based nanoconposites (Figs. 4-6). The shift in the luminescence maximum depends on the effective dielectric permittivity of the nanocrystal material. It is seen in Fig. 5 that the shift is where the maximum is larger for $\mathrm{Al}_{2} \mathrm{O}_{3}\left(\varepsilon_{\text {eff }}=5.68\right)$ than for $\mathrm{Y}_{2} \mathrm{O}_{3}$ $\left(\varepsilon_{\text {eff }}=6.41\right)$. Figure 5 shows that $\mathrm{ZnO}$ and $\mathrm{SnSbO}$ represent a group of materials in which the shift is negligible and independent of the volume fraction of inorganic inclusions. It is worth noting that these materials alone form type-II heterostructures in the polymers under investigation. In type-II heterostructures, the electrons can be captured into the nanocrystals or stored therein in the case of direct optical excitation inside the nanocrystals. The establishment of a net charge creates an electric field outside the nanocrystals, perturbing thereby the band diagram, as depicted in Fig. 8(c). This provides a route towards separation of the electronhole pair that make up an exciton. This explains the much lower luminescence intensity in SnSbO/CN-PPP compared to in the other nanocomposites which employ the same polymer matrix. For example, luminescence of nanocomposites $\mathrm{SnSbO}, \mathrm{Al}_{2} \mathrm{O}_{3}, \mathrm{ZnO}$, and $\mathrm{Y}_{2} \mathrm{O}_{3}$ with equal $(\sim 60 \%)$ volume concentration of nanocrystals has relative intensity of, respectively, 1, 3.8, 12.5, and 17.5. $\mathrm{ZnO} / \mathrm{CN}-\mathrm{PPP}$, which also forms a type-II heterostructure with CN-PPP, has a higher luminescence intensity, and it is attributable to direct luminescence from $\mathrm{ZnO}$, whose band gap is close to that of $\mathrm{CN}$ PPP.

The difference in dipole amplitude between PPV and CN-PPP is related to their molecular structure. Since the main contribution to the polarization energy is from the electron component, the dipolar amplitudes are determined by the extent of electron redistribution along the chains. For a single polymer chain the electron response to the electric field of an external charge will be anisotropic and have a much larger electronic shift along than normal to the chains. This shift must also depend on the electron energy in different parts of the chain. Since the electron energy near the benzene ring is higher than that near the vinylene group, ${ }^{27}$ large electron shifts along the PPV chain are suppressed. In CN-PPP the benzene rings are directly interconnected, the conditions for electrons are more uniform, and their shift can be larger. Furthermore, CN-PPP allows a larger transverse electron shift since the $\mathrm{CN}$ group is attached to the ring with a long bond.

Thus, dielectric inclusions influence the energy structure of a polymer by increasing (or decreasing) its band gap in the vicinity of inclusions. Similar variations can be expected for excitonic energy, which also depends on the distance between the exciton and the inclusion.

The band diagram in Fig. 8 shows that both excitons and unbound carriers will either be repelled from or attracted to the dielectric nanocrystals, depending on the relative polarization characteristics of the polymer and the dielectric. In the case of semiconductor quantum dots, rather than dielectric antidots, this will influence carrier capture by nanocrystals and, ultimately, the recombination of nonequilibrium carriers.

\section{CONCLUSIONS}

To summarize, we investigated the photoluminescence spectra of nanocomposites based on PPV and CN-PPP polymers with embedded nanoparticles of $\mathrm{Y}_{2} \mathrm{O}_{3}, \mathrm{Al}_{2} \mathrm{O}_{3}, \mathrm{ZnO}$, and $\mathrm{SnSbO}$. Dielectric nanoparticles noticeably change the photoluminescence spectra of PPV-based nanocomposites: the spectrum broadens, loses its vibronic structure, and shifts towards higher photon energies. The spectra of CN-PPPbased nanocomposites undergo much weaker changes in redshifting and broadening. The phenomena observed are explained by modification of the polarization component of energy for free carriers and excitons. As a result, in the vicinity of dielectric inclusions the positions of LUMO and HOMO levels and, hence, the band gap of polymers, vary. Depending on the relationship between the polymer and nanocrystal polarizability, the LUMO-HOMO gap can either increase or decrease. Hence, in constructing the band diagram of nanocomposites with embedded dielectric or semiconductor nanocrystals, variations of this gap in the vicinity of nanocrystals should be taken into account.

${ }^{1}$ A. D. Pomogailo, A. S. Rozenberg, and I. E. Uflyand, Nanoscale Metallic Particles in Polymers (Himiya, Moscow, 2000) (in Russian).

${ }^{2}$ M. C. Schlamp, X. Peng, and A. P. Alivisatos, J. Appl. Phys. 82, 5837 (1997).

${ }^{3}$ S. A. Carter, J. C. Scott, and P. J. Brock, Appl. Phys. Lett. 71, 1145 (1997).

${ }^{4}$ G. P. Banfi, V. Degiorgio, and D. Ricard, Adv. Phys. 47, 447 (1998).

${ }^{5}$ H. Mattoussi, B. O. Dabbousi, E. L. Thomas, M. G. Bawendi, and M. F. Rubner, J. Appl. Phys. 83, 7965 (1998).

${ }^{6}$ T. J. Savenije, M. J. W. Vermeulen, M. P. de Haas, and J. M. Warman, Sol. Energy Mater. Sol. Cells 61, 9 (2000).

${ }^{7}$ L. Bakueva, S. Musikhin, and E. H. Sargent, J. Nanosci. Nanotechnol. 1, 457 (2001).

${ }^{8}$ A. Shik, H. Ruda, and E. H. Sargent, J. Appl. Phys. 88, 3448 (2000).

${ }^{9}$ W.-P. Chang and W.-T. Whang, Polymer 37, 4229 (1996).

${ }^{10}$ S. Heun, R. F. Mahrt, A. Greiner, U. Lemmer, H. Bassler, D. A. Halliday, D. D. C. Bradley, P. L. Burn, and A. B. Holmes, J. Phys.: Condens. Matter 5, 247 (1993)

${ }^{11}$ M. Pope and C. E. Swenberg, Electronic Processes in Organic Crystals and Polymers (Oxford Science, New York, 1999).

${ }^{12}$ Y. Yang, Q. Pei, and A. J. Heeger, J. Appl. Phys. 79, 934 (1995).

${ }^{13}$ J. Robertson, J. Vac. Sci. Technol. 18, 1785 (2000).

${ }^{14}$ S. Liang, H. Sheng, Y. Liu, Y. Lu, and H. Shen, J. Cryst. Growth 225, 110 (2001).

${ }^{15}$ P. S. Nayar, J. Appl. Phys. 53, 1069 (1982).

${ }^{16}$ R. F. Dietz, J. J. Hopfield, and D. G. Thomas, J. Appl. Phys. 32, 2282 (1961).

${ }^{17}$ K. S. Mishra, K. H. Johnson, and P. C. Schmidt, Phys. Rev. B 51, 13972 (1995).

${ }^{18}$ G. Mangamma, V. Jayaramman, T. Gnanasekaran, and G. Periaswami, Sens. Actuators B 54, 133 (1999).

${ }^{19}$ Organic Electroluminescent Materials and Devices, edited by S. Miyata and H. S. Nalwa (Gordon and Breach, New York, 1997).

${ }^{20}$ P. K. H. Ho, J.-S. Kim, N. Tissler, and R. H. Friend, J. Chem. Phys. 115, 2709 (2001).

${ }^{21}$ S. Courric and V. H. Tran, Polymer 39, 2399 (1998).

${ }^{22}$ A. James and M. Lord, Index of Chemical and Physical Data (Van Nostrand Reinhold, New York, 1992).

${ }^{23}$ The Oxide Handbook, edited by G. V. Samsonov (IFI/Plenum Data, New York, 1982).

${ }^{24}$ Organic Electron Materials; Conjugated Polymers and Low Molecular Weight Organic Solids, edited by R. Farchioni and G. Grosso (Springer, Berlin, 2001).

${ }^{25}$ E. A. Silinsh, Organic Molecular Crystals (Springer, Berlin, 1980).

${ }^{26}$ Handbook of Conjugating Polymers, edited by T. A. Skotheim, R. L. Elsenbaumer, and J. R. Reynolds (Dekker, New York, 1998).

${ }^{27}$ M. Chandross, S. Mazumdar, S. Jeglinski, X. Wei, Z. V. Vardeny, E. W. Kwock, and T. M. Miller, Phys. Rev. B 50, 14702 (1994). 